\title{
Liraglutide and Metformin alone or combined therapy for type 2 diabetes patients complicated with coronary artery disease
}

Ying Liu ${ }^{1 *}$ Xia Jiang ${ }^{1}$ and Xin Chen ${ }^{2}$

\begin{abstract}
Background: This study is to compare the effects of Liraglutide and Metformin alone or combined treatment on the cardiac function in T2DM patients complicated with CAD.

Methods: 120 T2DM patients were included at Endocrinology Department of Tianjin First Center Hospital (Tianjin, China) from April 2012 to September 2013. The study contained two sections. Section 1: 30 patients in group 1 was treated with Liraglutide (Novo Nordisk) $(1.2 \mathrm{mg} / \mathrm{d}$ ), and 30 patients in group 2 with Metformin (Shiguibao) $(1500 \mathrm{mg} / \mathrm{d})$ for 24 weeks. Section 2: 30 patients in group1 was treated with Liraglutide $(1.8 \mathrm{mg} / \mathrm{d})$ and 30 in group 2 with Liraglutide $(1.2 \mathrm{mg} / \mathrm{d})$ plus Metformin (1500 mg/d) for 24 weeks. Fasting blood glucose (FBG), postprandial glucose (PPG), glycated hemoglobin ( $\mathrm{HbA1c})$, body mass index (BMI), blood pressure (BP), triglyceride (TG), total cholesterol (TC), low-density lipoprotein cholesterol (LDL-C), C reactive protein (CRP), left ventricular end-diastolic diameter (LVEDD), ejection fraction (EF) and the ratio of early (E) to late $(A)$ ventricular filling velocities (E/A ratio) were measured before and after the 24-week treatment.
\end{abstract}

Results: After 24-week treatment, when blood glucose level was controlled in 4 groups, Liraglutide alone treatment showed better improvements than on all measuring except TG in Section 1, however, combined treatment of Liraglutide and Metformin showed better improvements on all measuring except BMI, TG and BP in Section 2.

Conclusions: With similar glycemic control, the Liraglutide $(1.2 \mathrm{mg} / \mathrm{d})$ monotherapy showed the better effects than either Metformin alone, or combination of Liraglutide and Metformin on lipid metabolism and cardiovascular function.

Trial registration: This trial was registered at Chinese Clinical Trial Registry (chictr.org.cn) \# ChiCTR-IPR-16008578.

Keywords: Liraglutide, Metformin, GLP-1, Type 2 diabetes mellitus (T2DM), Coronary artery disease (CAD)

\section{Background}

Type 2 diabetes mellitus (T2DM) is commonly complicated with coronary artery disease (CAD), hypertension, stroke and heart failure [1]. As a result of small vessel disease and metabolic disorders, diabetes is associated with some forms of cardiomyopathy and congestive heart failure [2]. On the other hand, CAD accounts for about $80 \%$ of deaths in T2DM patients. Besides the glucose level, other risk factors include hypertension, dyslipidaemia, obesity and insulin resistance [3]. Although

\footnotetext{
* Correspondence: liuyingchristing@163.com

'Department of Endocrinology, Tianjin First Center Hospital, 24 Fukang Road, Nankai District, Tianjin 300192, China

Full list of author information is available at the end of the article
}

glycemic control represents the classical goal of diabetes therapy, the pathogenesis of the cardiovascular complications extends beyond hyperglycemia. Thus, from an individualized perspective, apart from glycemic control, improvement of cardiovascular function should also be taken into account for T2DM patients complicated with CAD.

Glucagon-like peptide-1 (GLP-1) is an endogenous insulinotropic peptide produced by intestinal epithelial endocrine L-cells and is considered to potentiate the incretin effect [4]. GLP-1 receptor agonists (RAs) improve glucose homeostasis through multifaceted action. Liraglutide, an analogue of GLP-1, maintains glucose homeostasis through the regulation of insulin and 
glucagon secretion [5]. Liraglutide also regulates hypertension, left ventricular function, cardiac steatosis, oxidative stress, and apoptosis both in human and animal models [6-8]. Metformin is the first-line medication for the treatment of type 2 diabetes, and induces muscles to take up glucose from the blood. Metformin has also been reported to reduce the multiple CAD risk factors such as free fatty acid (FFA), triglyceride (TG) and remnant lipoprotein cholesterol (RLP-C) [9]. Animal studies also demonstrated a protective role of Metformin in myocardial dysfunction [10]. Moreover, it was reported that GLP-1 infusion improves left ventricular ejection fraction and functional status in patients with chronic heart failure [11].

Thus, we investigated the efficacy of alone or combined therapy of Liraglutide or Metformin on the cardiovascular function of T2DM patients complicated with CAD.

\section{Methods}

\section{Study design}

We conducted a pilot study with section 1 and 2 . In section 1, 30 patients with T2DM were in Liraglutide monotherapy $(1.2 \mathrm{mg} / \mathrm{d})$ group and 30 patients with T2DM were in Metformin monotherapy $(1500 \mathrm{mg} / \mathrm{d}$ ) group. In section 2, 30 patients with T2DM were in Liraglutide monotherapy $(1.8 \mathrm{mg} / \mathrm{d})$ group and 30 patients with T2DM were in Liraglutide $(1.2 \mathrm{mg} / \mathrm{d}$ ) plus Metformin $(1500 \mathrm{mg} / \mathrm{d})$ group at the Department of Endocrinology of Tianjin First Center Hospital between April 2012 and September 2013. The study was approved by Ethics Committee of Tianjin First Center Hospital (No. 2014N0016LW), and was registered at Chinese Clinical Trial Registry (chictr.org.cn, No. ChiCTR-IPR-16008578). All patients provided written informed consent.

\section{Patients}

The diagnostic criteria for diabetes were: oral glucose tolerance test, fasting blood glucose $\geq 7 \mathrm{mmol} / \mathrm{L}, 2$-h postprandial glucose $(\mathrm{PPG}) \geq 11.1 \mathrm{mmol} / \mathrm{L}$ and $\mathrm{HbA} 1 \mathrm{c}$ $\geq 6.5 \%$ or $48 \mathrm{mmol} / \mathrm{L}$. According to Clinical Practice Guidelines by European Society of Cardiology in 2006 (coronary artery stenosis on angiography), the diagnosis of CAD included one of the following: 1) having the typical angina symptom and excluding aortic valve lesion; 2) having history of old myocardial infarction; 3) having history of acute myocardial infarction; 4) coronary angiography revealed that $>=70 \%$ of coronary artery stenosis. Exclusion criteria were: 1) Type I diabetes; 2) history of tuberculosis, viral hemorrhagic fevers, avian influenza, viral hepatitis, atypical pneumonia, dysentery, meningococcal meningitis, or any other chronic or acute infectious diseases that affect carbohydrate metabolism within the past 6 months; 3) present illness that interferes with carbohydrate and/or lipids metabolism (such as hormones); 4) severe heart failure, cardiac hypertrophy, rheumatic heart disease, valve disorder, myocarditis or endocarditis, or any other significant cardiovascular events; 5) not suitable for coronary angiography; 6) women during pregnancy, lactation, or planning for pregnancy; 7) taking diet pills within the past 6 months; 8) chronic liver dysfunction (alanine aminotransferase/aspartate aminotransferase $>2.5 \quad$ ULN) and/or chronic renal dysfunction (serum creatinine $>150 \mu \mathrm{mol} / \mathrm{L})$; 9) severe electrolyte disorders; 10) previous episodes of acute orchronic pancreatitis; 11) history of tumor or any other severe diseases that are not suitable to be included as judged by the investigator.

\section{Treatment plans}

Drugs used in the study included Liraglutid, $18 \mathrm{mg} /$ $3 \mathrm{ml} /$ pen (pre-filled pen), (Novo Nordisk, Beijing, China) and Metformin (Glucophage) $0.5 \mathrm{mg} /$ pill (Shanghai Shiguibao pharmaceutical Co. LTD, Shanghai, China).

All patients were instructed by the investigator for food intake, exercise, drug administration, fingertip blood glucose (FBG) measurement (Bayer Blood Glucose Monitoring System), and records of treatment for hypoglycemia and/or any adverse effects. All preexisting treatment for hypertension, hypercholesterolemia, anticoagulant and coronary dilation were maintained throughout the study. In addition, food intake was controlled and regular exercise was maintained. No drugs that potentially interfered with the outcomes were used. Ultrasound cardiography (UCG) and blood pressure were measured at the hospital.

Two-drug effects on cardiovascular diseases in T2DM patients complicated with CAD were compared between Sections and intra-each Section with glucose and lipid metabolism indicators.

\section{Section 1}

Thirty patients in Liraglutide group were daily injected with $0.6 \mathrm{mg}$ of Liraglutide before breakfast. Fasting plasma glucose (FPG) was measured 7-day later. The dosage was increased to $1.2 \mathrm{mg} / \mathrm{d}$ if $\mathrm{FPG}>7.0 \mathrm{mmol} / \mathrm{L}$ or 2 -h PPG > $11.1 \mathrm{mmol} / \mathrm{L}$, otherwise it was remained at $0.6 \mathrm{mg} / \mathrm{d}$. After another 7 days, the dosage was increased to $1.8 \mathrm{mg} / \mathrm{d}$ if FPG $>7.0 \mathrm{mmol} / \mathrm{L}$ or 2 -h PPG $>11.1 \mathrm{mmol} / \mathrm{L}$, otherwise it remained at $1.2 \mathrm{mg} / \mathrm{d}$. The average dose of Liraglutide was $1.2 \mathrm{mg} / \mathrm{d}$. 30 patients in Metformin group took orally Metformin with starting dosage of $500 \mathrm{mg}$ twice daily before breakfast and supper. The dosage was adjusted every other day if FPG > 7.0 mmol/L or 2-h PPG > $11.1 \mathrm{mmol} / \mathrm{L}$. The maximum dose was $2000 \mathrm{mg} / \mathrm{d}$, with the average dose of $1500 \mathrm{mg} / \mathrm{d}$. 


\section{Section 2}

Patients were was daily injected with the $0.6 \mathrm{mg}$ of Liraglutide before breakfast. FPG was measured 7-day later. The dosage was increased to $1.2 \mathrm{mg} / \mathrm{d}$ if FPG > $7.0 \mathrm{mmol} / \mathrm{L}$, or $2-\mathrm{h}$ PPG $>11.1 \mathrm{mmol} / \mathrm{L}$, otherwise the patients were excluded. After another 7 days, only patients with FPG $>7.0 \mathrm{mmol} / \mathrm{L}$ or $2-\mathrm{h}$ PPG $>11.1 \mathrm{mmol} / \mathrm{L}$ were remained in the study, who were randomized to either Liraglutide monotherapy $(n=30)$ or the combination therapy of Liraglutide and Metformin $(n=30)$. The dosage of Liraglutide was increased to $1.8 \mathrm{mg} / \mathrm{d}$ in the monotherapy group, while Liraglutide was maintained in $1.2 \mathrm{mg} / \mathrm{d}$ in combined therapy group. The dosage of Metformin was added to the combined therapy group according to the same strategy used in Section 1.

For patients with suboptimal glucose control at the start of the trial, concomitant use of $\alpha$ - glucosidase inhibitors was permitted at the discretion of the investigator.

Patients were randomly grouped according to the randomization number. The blood test, echocardiography, and blood pressure were carried out and analyzed by the technicians, who were blinded to the treatment allocation.

\section{Study outcomes}

The primary outcomes included a total of 8 measurements of FBG (before and $2 \mathrm{~h}$ after 3 meals, before bedtime, and at midnight) taken in the same day once a week. Other parameters, including FBG, PPG, HbA1c, blood pressure, body mass index (BMI), TG, total cholesterol (TC), low-density lipoprotein cholesterol (LDL-C), C-reactive protein (CRP), left ventricular enddiastolic diameter (LVEDD), ejection fraction (EF) and $\mathrm{E} / \mathrm{A}$ ratio were recorded at baseline before treatment and at 24-week after treatment. FBG between 5.0$7.0 \mathrm{mmol} / \mathrm{L}$, PPG between $7.8-11.1 \mathrm{mmol} / \mathrm{L}$ and HbAlc $<7.0 \%$ were considered normal.

The secondary outcomes were:1) severe hypoglycemia (requiring assistance from others); 2) moderate hypoglycemia (showing symptoms of hypoglycemia with FBG $<3.9 \mathrm{mmol} / \mathrm{L}$, which can be treated with food intake without need of other's assistance); 3) mild hypoglycemia (showing symptoms of hypoglycemia with FBG $>3.9 \mathrm{mmol} / \mathrm{L})$.

The adverse events, like nausea, vomiting, diarrhea, rash, red/itchy/inflamed skin, and induration or irritation of injection site skin were recorded.

\section{Data management and statistical analysis}

Data were entered into an Excel (Micro-soft office 2000) database and were proofed for entry errors. The database was subsequently locked, imported into SPSS for Windows (IBM SPSS Statistics for Windows, Version
11.0. Armonk, NY: IBM Corp.) formatted and analyzed. BMI, FBG, TG, TC, LDL-C, PPG, HbA1c, SBP, DBP, CRP, LVEDD, EF and E/A ratio were normally distributed as continuous variables, and were analyzed with Student's t-test between groups. Independent samples t-test was performed for the changes from baseline to week 24 of all parameters. Categorical data were analyzed by $x^{2}$ tests. $\alpha$ was set at 0.05 for all tests.

\section{Results}

Once Section 1 analysis was completed, the patients for Section 2 were recruited. With 76 patients screened for Section 1, 60 met eligibility criteria and were evenly grouped into Liraglutide or Metformin monotherapy. Of the 84 patients screened for Section 2, 60 met eligibility criteria and were grouped into singled (monotherapy) or combined (dual) therapy (Fig. 1). Baseline demographic and clinical characteristics were similar between groups (Table 1). Patients in Section 1 and 2 were aged between 26 and 88 years (median, 59 years) and between 27 and 82 years (median, 60 years), respectively. The mean duration of diabetes was $8 \pm 5$ years in both Sections.

\section{Saction1: Liraglutide vs. Metformin monotherapy}

After 24 weeks, Liraglutide monotherapy significantly decreased the plasma glucose from $13.8 \pm 5.1$ to $7.9 \pm$ $3.3 \mathrm{mmol} / \mathrm{L}, \mathrm{HbA} 1 \mathrm{cfrom} 9.0 \pm 1.3 \%$ (or $75 \pm 14 \mathrm{mmol} / \mathrm{L}$ ) to $6.8 \pm 0.8 \%$ (or $51 \pm 9 \mathrm{mmol} / \mathrm{L}$ ); while Metformin significantly decreased the plasma glucose from $13.7 \pm 4.8$ to $8.2 \pm 3.5 \mathrm{mmol} / \mathrm{L}$ and $\mathrm{HbA} 1 \mathrm{c}$ from $9.1 \pm 1.1 \%$ (or 96 $\pm 12 \mathrm{mmol} / \mathrm{L}$ ) to $6.9 \pm 0.7 \%$ (or $52 \pm 8 \mathrm{mmol} / \mathrm{L}$ ). Obviously, no significant differences on decreases of the plasma glucose and HbA1c were seen between two treatments. Some risk factors for CAD were significantly decreased with both treatments. Plasma TG was decreased from $2.8 \pm 0.7$ to $2.4 \pm 0.4 \mathrm{mmol} / \mathrm{L}$, TC from 6.2 \pm 0.8 to $5.4 \pm 0.7 \mathrm{mmol} / \mathrm{L}$, and LDL-C from $4.1 \pm 0.8$ to $3.5 \pm 0.5 \mathrm{mmol} / \mathrm{L}$ in Liraglutide group; while plasma TG was significantly decreased from $2.9 \pm 0.6$ to $2.6 \pm$ $0.5 \mathrm{mmol} / \mathrm{L}$, TC from $6.3 \pm 0.9$ to $5.7 \pm 0.8 \mathrm{mmol} / \mathrm{L}$, LDL-C from $4.2 \pm 0.7$ to $3.8 \pm 0.6 \mathrm{mmol} / \mathrm{L}$ in Metformin group (Tables 1 and 2). The two medications showed the equal efficacy on decreasing plasma glucose. To our surprise, Liraglutide $(1.2 \mathrm{mg} / \mathrm{d})$ alone showed better improvements on the lipid metabolism and the cardiovascular function, including TG, LDL-C, CRP, SBP, DBP, LVEDD, EF and E/A ratio (Tables 2 and 3).

\section{Section 2: Monotherapy vs. combined therapy}

Due to a better efficacy of Liraglutide shown in Section 1, higher dose of Liraglutide $(1.8 \mathrm{mg} / \mathrm{d})$ alone was chosen for study in Section 2, and Liraglutide $(1.2 \mathrm{mg} / \mathrm{d})$ plus Metformin was selected for combined therapy. After 24-week treatment, plasma glucose of $7.9 \pm$ 


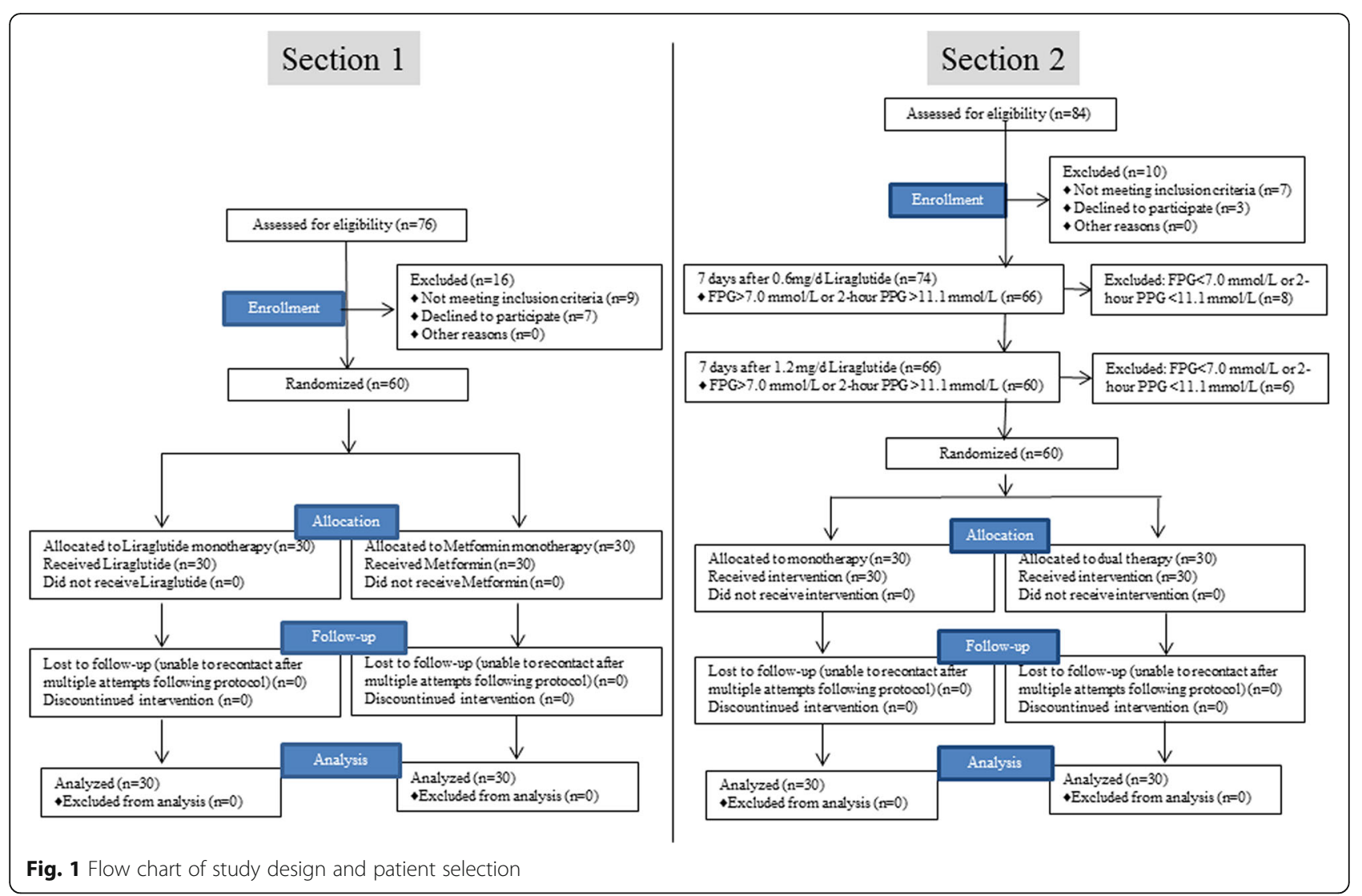

$3.4 \mathrm{mmol} / \mathrm{L}$ in monotherapy and $7.7 \pm 3.2 \mathrm{mmol} / \mathrm{L}$ in dual therapy, and HbA1c of $6.8 \pm 0.9 \%$ (or $51 \pm 9 \mathrm{mmol} / \mathrm{L}$ ) in monotherapy and $6.7 \pm 0.7 \%$ (or $50 \pm 8 \mathrm{mmol} / \mathrm{L}$ ) in dual therapy were significantly decreased when compared with the levels of baseline, in which averages of plasma glucose and HbA1c from two sections at baseline vs. 24-week treatment were $9.2 \pm 0.2$ vs. $6.8 \pm 0.1 \%$. However, there was no significant difference on glycemic control between groups in Section 2 (Tables 2 and 3).

However, in section 2, combined treatment of Liraglutide and Metformin showed the better improvements only on TC, LVEDD and E/A ratio when compared with Liraglutide $(1.8 \mathrm{mg} / \mathrm{d})$ alone treatment (Table 2$)$.

In addition, regarding the adverse events associated with each treatment, less events such as transient anorexia, nausea, and vomiting were observed in the dual therapy than in Liraglutide monotherapy, which were shown in Table 4.

\section{Discussion}

Both Liraglutide and Metformin have been extensively studied on the basis of glycemic control. The current study was focused on the cardiovascular function analyses with Liraglutide and/or Metformin treatment in T2DM patients complicated with CAD. We have found that, with comparable glycemic levels, both Liraglutide monotherapy and Metformin monotherapy could significantly improve plasma lipid profile, BMI, CRP, and cardiac functions. However, Liraglutide $(1.2 \mathrm{mg} / \mathrm{d})$ monotherapy significantly improved the LDL-C, CRP, $\mathrm{BP}$, LVEDD, EF percentage and E/A ratio, compared with Metformin monotherapy. Based on the results, we further compared the higher dose of Liraglutide $(1.8 \mathrm{mg} / \mathrm{d})$ monotherapy with the dual therapy of low dose Liraglutide $(1.2 \mathrm{mg} / \mathrm{d})$ plus Metformin. To our surprise, not only the dual therapy but also the higher dose of Liraglutide $(1.8 \mathrm{mg} / \mathrm{d})$ monotherapy showed less improvements on the lipid metabolism and the cardiovascular function, compared with Liraglutide $(1.2 \mathrm{mg} / \mathrm{d})$ monotherapy. It is understandable that as analogue of GLP-1, Liraglutide may slow the rate of absorption of nutrients into the blood stream by reducing gastric emptying and may directly reduce food intake, including decreasing lipids intake and absorption. A recent study of 36month LEADER trial revealed that Liraglutide improved cardiovascular outcomes in T2DM patients [12]. It was also reported that an addition of 5-week infusion of GLP-1 to standard therapy in patients with New York Heart Association class III/IV heart failure significantly improved cardiac function, as indicated by left ventricular ejection fraction, maximum myocardial ventilation oxygen consumption, and 6-min walk distance [11]. Pre- 
Table 1 Demographic and baseline characteristics between groups in each Section ( $n=30$ for each group)

\begin{tabular}{|c|c|c|c|c|c|c|}
\hline \multirow[t]{2}{*}{ Variables } & \multicolumn{3}{|l|}{ Section 1} & \multicolumn{3}{|l|}{ Section 2} \\
\hline & Liraglutide monotherapy & Metformin monotherapy & $P$ & $\begin{array}{l}\text { Liraglutide }(1.8 \mathrm{mg} / \mathrm{d}) \\
\text { monotherapy }\end{array}$ & $\begin{array}{l}\text { Liraglutide plus Metformin } \\
\text { dual therapy }\end{array}$ & $P$ \\
\hline Male, n (\%) & $16(53.3)$ & $17(46.7)$ & 0.795 & $16(53.3)$ & $17(46.7)$ & 0.795 \\
\hline Duration of diabetes (year) & $8 \pm 5$ & $7 \pm 4$ & 0.396 & $8 \pm 5$ & $9 \pm 6$ & 0.486 \\
\hline Age at initial visit (year) & $58 \pm 15$ & $59 \pm 17$ & 0.810 & $58 \pm 16$ & $57 \pm 14$ & 0.798 \\
\hline \multicolumn{7}{|l|}{ Pre-medication } \\
\hline Statins (n) & 2 & 3 & 0.640 & 4 & 4 & 1.000 \\
\hline Fibrates (n) & 2 & 1 & 0.554 & 3 & 2 & 0.640 \\
\hline ARB (n) & 4 & 3 & 0.688 & 5 & 5 & 1.000 \\
\hline ACEI (n) & 1 & 2 & 0.554 & 1 & 0 & 0.313 \\
\hline Calcium antagonists (n) & 2 & 2 & 1.000 & 2 & 3 & 0.640 \\
\hline Diuretics (n) & 0 & 0 & - & 0 & 1 & 0.313 \\
\hline BMI $\left(\mathrm{kg} / \mathrm{m}^{2}\right)$ & $29.56 \pm 1.68$ & $29.63 \pm 1.75$ & 0.875 & $29.78 \pm 1.85$ & $29.66 \pm 1.78$ & 0.799 \\
\hline $\begin{array}{l}\text { FPG (mmol/L) } \\
\mathrm{HbA1c}\end{array}$ & $9.3 \pm 1.7$ & $9.1 \pm 2.0$ & $\begin{array}{l}0.678 \\
0.749\end{array}$ & $9.0 \pm 2.1$ & $9.3 \pm 1.7$ & $\begin{array}{l}0.546 \\
0.758\end{array}$ \\
\hline$\%$ & $9.0 \pm 1.3$ & $9.1 \pm 1.1$ & & $9.3 \pm 1.3$ & $9.4 \pm 1.2$ & \\
\hline $\mathrm{mmol} / \mathrm{L}$ & $75 \pm 14$ & $76 \pm 12$ & & $78 \pm 14$ & $79 \pm 13$ & \\
\hline PPG (mmol/L) & $13.8 \pm 5.1$ & $13.7 \pm 4.8$ & 0.938 & $13.8 \pm 4.9$ & $13.6 \pm 5.3$ & 0.880 \\
\hline CRP (mg/L) & $9.5 \pm 2.2$ & $9.7 \pm 2.4$ & 0.738 & $9.5 \pm 2.2$ & $9.7 \pm 2.4$ & 0.738 \\
\hline TG (mmol/L) & $2.8 \pm 0.7$ & $2.9 \pm 0.6$ & 0.555 & $2.8 \pm 0.6$ & $2.9 \pm 0.8$ & 0.586 \\
\hline TC (mmol/L) & $6.2 \pm 0.8$ & $6.3 \pm 0.9$ & 0.651 & $6.4 \pm 0.8$ & $6.3 \pm 0.7$ & 0.608 \\
\hline LDL-C (mmol/L) & $4.1 \pm 0.8$ & $4.2 \pm 0.7$ & 0.608 & $4.3 \pm 0.8$ & $4.2 \pm 0.7$ & 0.608 \\
\hline $\mathrm{SBP}(\mathrm{mmHg})$ & $145 \pm 9$ & $144 \pm 8$ & 0.651 & $146 \pm 7$ & $144 \pm 8$ & 0.307 \\
\hline $\mathrm{DBP}(\mathrm{mmHg})$ & $92 \pm 5$ & $93 \pm 7$ & 0.527 & $94 \pm 8$ & $93 \pm 7$ & 0.608 \\
\hline LVEDD (mm) & $55 \pm 7$ & $56 \pm 9$ & 0.633 & $59 \pm 7$ & $58 \pm 9$ & 0.633 \\
\hline EF (\%) & $48 \pm 5$ & $47 \pm 4$ & 0.396 & $46 \pm 5$ & $47 \pm 4$ & 0.396 \\
\hline E/A ratio & $0.75 \pm 0.09$ & $0.72 \pm 0.07$ & 0.155 & $0.73 \pm 0.06$ & $0.75 \pm 0.07$ & 0.240 \\
\hline
\end{tabular}

Data are mean \pm SD, unless otherwise noted; Abbreviations: BMI body mass index, TG triglyceride, $T C$ total cholesterol, $L D L$-C low-density lipoprotein cholesterol, PPG postprandial glucose, SBP systolic blood pressure, DBP diastolic blood pressure, CRP C-reactive protein, $L V E D D$ left ventricular end-diastolic diameter, EF ejection fraction

clinical and clinical studies have also revealed the beneficial effect of Liraglutide on lipid metabolism/profile and endothelial function in T2DM patients [12-14]. Possible underlying mechanisms include alleviated oxidative stress and cardiomyocytes apoptosis by GLP-1, prevention of micro-vascular diseases related to diabetes, protection of cardiac micro-vascular endothelial cells against hypoxia/re-oxygenation injury, regulation of calcium homeostasis and electrophysiological activities of cardiomyocytes [12, 13, 15-19].

GLP-1's actions are mediated through the G-proteincoupled GLP-1 receptor. GLP-1 or GLP-1 receptor agonist decreases food intake, slows gastric emptying, and reduces body weight through its effects on energy expenditure. As well reviewed, liraglutide has been demonstrated to reduce food intake, promote weight loss, and improve indices of metabolic function in both animal and human studies, and the primary mechanisms associated with these effects are proposed to be due to actions of GLP-1 on peripheral and central pathways that affect food intake and metabolism via hindbrain and hypothalamic activation, as well as those brain areas associated with motivation and reward processes [20]. In patients with Type 2 diabetes, well controlled with metformin monotherapy, addition of liraglutide improves several cardiovascular risk markers beyond glycaemic control [21]. These studies, together with our data, support the effect of Liraglutide on improving the cardiovascular function of T2DM patients besides glycemic control.

The ability of Metformin to reduce hepatic glucose production and increase skeletal muscle glucose uptake has made it as one of the major first-line therapies for T2DM [22, 23]. It was also reported that Metformin could reduce insulin resistance, lower blood pressure, improve circulating lipid profile, and prevent myocardial 
Table 2 Clinical characteristics of patients at 24-week after medication treatment ( $n=30$ for each group)

\begin{tabular}{|c|c|c|c|c|c|c|}
\hline \multirow[t]{2}{*}{ Variables } & \multicolumn{3}{|l|}{ Section 1} & \multicolumn{3}{|l|}{ Section 2} \\
\hline & $\begin{array}{l}\text { Liraglutide } \\
\text { monotherapy }\end{array}$ & $\begin{array}{l}\text { Metformin } \\
\text { monotherapy }\end{array}$ & $P$ & $\begin{array}{l}\text { Liraglutide }(1.8 \mathrm{mg} / \mathrm{d}) \\
\text { monotherapy }\end{array}$ & $\begin{array}{l}\text { Liraglutide plus Metformin } \\
\text { dual therapy }\end{array}$ & $P$ \\
\hline BMI $\left(\mathrm{kg} / \mathrm{m}^{2}\right)$ & $28.37 \pm 1.72$ & $28.70 \pm 1.87$ & 0.480 & $28.65 \pm 1.77$ & $28.42 \pm 1.74$ & 0.614 \\
\hline $\begin{array}{l}\mathrm{FPG} \\
\mathrm{c}\end{array}$ & $6.0 \pm 1.2$ & $6.2 \pm 1.0$ & $\begin{array}{l}0.701 \\
0.608\end{array}$ & $6.0 \pm 1.2$ & $6.2 \pm 1.0$ & $\begin{array}{l}0.486 \\
0.633\end{array}$ \\
\hline$\%$ & $6.8 \pm 0.8$ & $6.9 \pm 0.7$ & & $6.8 \pm 0.9$ & $6.7 \pm 0.7$ & \\
\hline $\mathrm{mmol} / \mathrm{L}$ & $51 \pm 9$ & $52 \pm 8$ & & $51 \pm 10$ & $50 \pm 8$ & \\
\hline PPG (mmol/L) & $7.9 \pm 3.3$ & $8.2 \pm 3.5$ & 0.734 & $7.9 \pm 3.4$ & $7.7 \pm 3.2$ & 0.815 \\
\hline TG $(\mathrm{mmol} / \mathrm{L})$ & $2.4 \pm 0.4$ & $2.6 \pm 0.5$ & 0.093 & $2.5 \pm 0.4$ & $2.4 \pm 0.5$ & 0.396 \\
\hline TC (mmol/L) & $5.4 \pm 0.7$ & $5.7 \pm 0.8$ & 0.128 & $5.7 \pm 0.7$ & $5.3 \pm 0.6$ & 0.021 \\
\hline LDL-C (mmol/L) & $3.5 \pm 0.5$ & $3.8 \pm 0.6$ & 0.040 & $3.7 \pm 0.7$ & $3.4 \pm 0.6$ & 0.080 \\
\hline CRP (mg/L) & $5.1 \pm 1.5$ & $7.2 \pm 1.7$ & $<0.001$ & $5.5 \pm 1.6$ & $5.2 \pm 1.3$ & 0.429 \\
\hline SBP $(\mathrm{mmHg})$ & $134 \pm 7$ & $141 \pm 7$ & $<0.001$ & $135 \pm 7$ & $132 \pm 8$ & 0.127 \\
\hline $\mathrm{DBP}(\mathrm{mmHg})$ & $86 \pm 6$ & $91 \pm 6$ & 0.002 & $87 \pm 6$ & $86 \pm 5$ & 0.486 \\
\hline LVEDD (mm) & $46 \pm 6$ & $50 \pm 7$ & 0.021 & $52 \pm 8$ & $48 \pm 7$ & 0.044 \\
\hline EF (\%) & $53 \pm 5$ & $50 \pm 6$ & 0.040 & $52 \pm 5$ & $54 \pm 6$ & 0.166 \\
\hline E/A ratio & $0.92 \pm 0.08$ & $0.77 \pm 0.09$ & $<0.001$ & $0.88 \pm 0.08$ & $0.93 \pm 0.09$ & 0.027 \\
\hline
\end{tabular}

Data are mean \pm SD; Abbreviations: BMI body mass index, TG triglyceride, TC total cholesterol, $L D L-C$ low-density lipoprotein cholesterol, $P P G$ postprandial glucose, $S B P$ systolic blood pressure, DBP diastolic blood pressure, CRP C-reactive protein, $L V E D D$ left ventricular end-diastolic diameter, EF ejection fraction

infarction and stroke in patients with diabetes [24-31]. In line with these results, the current study also demonstrated that Metformin improve lipid profile and cardiovascular function beyond glycemic control. It was reported that Metformin could inhibit the production of triglycerides and cholesterol, and stimulates fatty acid oxidation, preventing the progression of nonalcoholic fatty liver disease [32, 33]. A recent report demonstrated a significant association between metformin response and TG, TC, HDL-C and LDL-C [34]. The glucoselowering property alone cannot account for cardiovascular benefit [26]. Accumulating evidences suggest the inhibition of pro-inflammatory responses, reduction of smooth muscle cell contractility, or increase of nitric oxide as possible mechanisms $[35,36]$.

Many studies were conducted to investigate the synergistic effect of different drugs. Liraglutide or Metformin has previously been studied to combine with other drugs

Table 3 Changes of plasma HbA1c, blood lipids and cardiac function between Baseline and End of Study (week 24)

\begin{tabular}{|c|c|c|c|c|c|c|}
\hline Variables & $\begin{array}{l}\text { Liraglutide } \\
\text { monotherapy }\end{array}$ & $\begin{array}{l}\text { Metformin } \\
\text { monotherapy }\end{array}$ & $P$ & $\begin{array}{l}\text { Liraglutide }(1.8 \mathrm{mg} / \mathrm{d}) \\
\text { monotherapy }\end{array}$ & $\begin{array}{l}\text { Liraglutide plus Metformin } \\
\text { dual therapy }\end{array}$ & $P$ \\
\hline $\mathrm{BMI}\left(\mathrm{kg} / \mathrm{m}^{2}\right)$ & $-1.07 \pm 0.23$ & $-0.73 \pm 0.14$ & $<0.001$ & $-1.13 \pm 0.16$ & $-1.20 \pm 0.21$ & 0.152 \\
\hline HbA1c (\%) & & & 0.278 & & & 0.093 \\
\hline$\%$ & $-2.6 \pm 0.3$ & $-2.5 \pm 0.4$ & & $-2.6 \pm 0.4$ & $-2.8 \pm 0.5$ & \\
\hline $\mathrm{mmol} / \mathrm{mol}$ & $-28 \pm 3$ & $-27 \pm 4$ & & $-28 \pm 0.4$ & $-31 \pm 5$ & \\
\hline PPG (mmol/L) & $-5.8 \pm 1.7$ & $-5.5 \pm 1.6$ & 0.484 & $-5.4 \pm 1.5$ & $-5.7 \pm 1.6$ & 0.459 \\
\hline TC (mmol/L) & $-0.7 \pm 0.4$ & $-0.5 \pm 0.3$ & 0.033 & $-0.7 \pm 0.3$ & $-0.9 \pm 0.4$ & 0.033 \\
\hline LDL-C (mmol/L) & $-0.6 \pm 0.3$ & $-0.4 \pm 0.2$ & 0.003 & $-0.5 \pm 0.3$ & $-0.8 \pm 0.4$ & 0.002 \\
\hline CRP (mg/L) & $-4.3 \pm 1.2$ & $-2.4 \pm 1.0$ & $<0.001$ & $-4.1 \pm 0.8$ & $-4.8 \pm 1.0$ & 0.004 \\
\hline SBP (mmHg) & $-11 \pm 4$ & $-4 \pm 2$ & $<0.001$ & $-11 \pm 3$ & $-12 \pm 4$ & 0.278 \\
\hline $\mathrm{DBP}(\mathrm{mmHg})$ & $-6 \pm 3$ & $-3 \pm 1$ & $<0.001$ & $-6 \pm 3$ & $-7 \pm 4$ & 0.278 \\
\hline LVEDD (mm) & $-9 \pm 4$ & $-5 \pm 3$ & $<0.001$ & $-8 \pm 3$ & $-10 \pm 4$ & 0.033 \\
\hline EF (\%) & $5 \pm 3$ & $3 \pm 2$ & 0.004 & $5 \pm 2$ & $7 \pm 3$ & 0.004 \\
\hline E/A ratio & $0.16 \pm 0.04$ & $0.05 \pm 0.02$ & $<0.001$ & $0.14 \pm 0.02$ & $0.18 \pm 0.04$ & $<0.001$ \\
\hline
\end{tabular}

Abbreviations: BMI body mass index, TG triglyceride, TC total cholesterol, LDL-C low-density lipoprotein cholesterol, PPG postprandial glucose, SBP systolic blood pressure, $D B P$ diastolic blood pressure, CRP C-reactive protein, $L V E D D$ left ventricular end-diastolic diameter, $E F$ ejection fraction 
Table 4 Adverse Events Caused with Treatments (n (\%))

\begin{tabular}{|c|c|c|c|c|c|c|}
\hline \multirow[t]{2}{*}{ Adverse Events } & \multicolumn{3}{|l|}{ Section 1} & \multicolumn{3}{|l|}{ Section 2} \\
\hline & $\begin{array}{l}\text { Liraglutide } \\
\text { monotherapy } \\
n=30\end{array}$ & $\begin{array}{l}\text { Metformin } \\
\text { monotherapy } \\
n=30\end{array}$ & $P$ & $\begin{array}{l}\text { Liraglutide }(1.8 \mathrm{mg} / \mathrm{d}) \\
\text { monotherapy } \\
n=30\end{array}$ & $\begin{array}{l}\text { Liraglutide plus Metformin } \\
\text { dual therapy } \\
n=30\end{array}$ & $P$ \\
\hline $\begin{array}{l}\text { Transient anorexia, nausea } \\
\text { or vomit }\end{array}$ & $5(16.7)$ & $7(23.3)$ & 0.519 & $6(20.0)$ & $14(46.7)$ & 0.029 \\
\hline Transient diarrhea & $2(6.7)$ & $2(6.7)$ & 1.000 & $3(10.0)$ & $1(3.3)$ & 0.612 \\
\hline Hypoglycemia & $1(3.3)$ & $1(3.3)$ & 1.000 & $4(13.3)$ & $3(10.0)$ & 1.000 \\
\hline $\begin{array}{l}\text { Injection site skin induration } \\
\text { and irritation }\end{array}$ & $1(3.3)$ & $0(3.3)$ & 0.313 & $1(3.3)$ & $2(6.7)$ & 1.000 \\
\hline
\end{tabular}

such as thiazolidinedione (TZD) and sulphonylurea [37-39]. All these dual and triple therapy showed, not only the more effective on decreasing blood glucose level, but also on reducing body weight, BP, BMI, compared with monotherapy. Theoretically, combined dual or triple drug therapy should produce a synergetic effect, which must be better than monotherapy. However, it remains unknown about the mechanism of the Liraglutide $(1.2 \mathrm{mg} / \mathrm{d})$ showed the better improvements on the lipid profiles and the cardiac function than either Liraglutide $(1.8 \mathrm{mg} / \mathrm{d})$ or dual therapy, so future studies are needed.

The most common adverse events associated with GLP-1 RAs were nausea, vomiting, and diarrhea, the causes of which were thought to be gastric emptying or the involved central nervous system. [40] To achieve similar glycemic control, a lower dose of Liraglutide was needed in the dual therapy. Not surprisingly, with similar glycemic control in T2DM patients complicated with $\mathrm{CAD}$, the occurrence of adverse events were significantly lower in the dual therapy, suggesting underlying advantage of dual therapy over monotherapy.

The limitation of the study were: 1) the sample size was relatively small, indicating less statistical power, lower chance of discovering genuine effects, and the possible exaggerated estimate [22]; 2) only one time point (24 weeks after treatment) was assessed, while T2DM complicated with CAD is a chronic disease, a longer-term observation would be of good value.

3) Recently, GLP-1 based therapies also have the potential to be linked to cancer, specifically thyroid cancer and pancreatic cancer [41]. However, no cancer risk was found with Liraglutide treatment in the present study.

\section{Conclusion}

In summary, the Liraglutide $(1.2 \mathrm{mg} / \mathrm{d})$ monotherapy showed the better effects than either Metformin alone, or combination of Liraglutide and Metformin on lipid metabolism and cardiovascular function in patients with similar glycemic control.

\begin{abstract}
Abbreviations
BMI: Body mass index; BP: Blood pressure; CAD: Coronary artery disease; CRP: C reactive protein; EF: Ejection fraction; FBG: Fasting blood glucose; FFA: Free fatty acid; GLP-1: Glucagon-like peptide-1; HbA1c: Glycated hemoglobin; LDL-C: Low-density lipoprotein cholesterol; LVEDD: Left ventricular end-diastolic diameter; PPG: Postprandial glucose; RAs: Receptor agonists; RLP-C: remnant lipoprotein cholesterol; T2DM: Type 2 diabetes mellitus; TC: Total cholesterol; TG: Triglyceride; TZD: Thiazolidinedione; UCG: Ultrasound cardiography
\end{abstract}

\section{Acknowledgements}

None declared.

\section{Funding}

The study was funded by the Endocrinology Department of Tianjin First Center Hospital. The funder of the study had no role in the study design, data collection, data analysis, data interpretation, or writing of the manuscript.

\section{Availability of data and materials}

The datasets supporting the conclusions of this article are included within the article.

\section{Authors' contributions}

YL contributed to the study design, XJ prepared the manuscript, XC perform the data analysis, all the authors made the final approval.

\section{Ethics approval and consent to participate}

The study protocol was approved by the Ethic Committee of the Tianjin First Center Hospital and conducted in accordance with Helsinki's Declaration. All the patients gave their written information consent.

Consent for publication

Not applicable.

\section{Competing interests}

The authors declare that they have no competing interests.

\section{Publisher's Note}

Springer Nature remains neutral with regard to jurisdictional claims in published maps and institutional affiliations.

\section{Author details}

'Department of Endocrinology, Tianjin First Center Hospital, 24 Fukang Road, Nankai District, Tianjin 300192, China. ${ }^{2}$ Department of Cardiovascular Medicine, Tianjin First Center Hospital, Tianjin 300192, China.

Received: 7 September 2017 Accepted: 5 November 2017 Published online: 02 December 2017

\section{References}

1. Prevalence of small vessel and large vessel disease in diabetic patients from 14 centres. The World Health Organisation Multinational Study of Vascular Disease in Diabetics. Diabetes Drafting Group. Diabetologia, 1985. 28 Suppl: p. $615-40$. 
2. Kannel WB, Hjortland M, Castelli WP. Role of diabetes in congestive heart failure: the Framingham study. Am J Cardiol. 1974;34(1):29-34.

3. Martin-Timon I, et al. Type 2 diabetes and cardiovascular disease: have all risk factors the same strength? World J Diabetes. 2014;5(4):444-70.

4. Yabe D, Seino Y. Two incretin hormones GLP-1 and GIP: comparison of their actions in insulin secretion and beta cell preservation. Prog Biophys Mol Biol. 2011;107(2):248-56.

5. Zheng $Y$, et al. Variants of NLRP3 gene are associated with insulin resistance in Chinese Han population with type-2 diabetes. Gene. 2013;530(1):151-4.

6. Hiramatsu T, et al. Liraglutide improves Glycemic and blood pressure control and ameliorates progression of left ventricular hypertrophy in patients with type 2 diabetes mellitus on peritoneal dialysis. Ther Apher Dial. 2015;19(6):598-605.

7. Chen WR, et al. Effects of liraglutide on left ventricular function in patients with ST-segment elevation myocardial infarction undergoing primary percutaneous coronary intervention. Am Heart J. 2015;170(5): 845-54

8. Inoue T, et al. GLP-1 analog liraglutide protects against cardiac steatosis, oxidative stress and apoptosis in streptozotocin-induced diabetic rats. Atherosclerosis. 2015;240(1):250-9.

9. Ajjan RA, Grant PJ. Cardiovascular disease prevention in patients with type 2 diabetes: the role of oral anti-diabetic agents. Diab Vasc Dis Res. 2006;3(3):147-58.

10. Vaez H, et al. Cardioprotective effect of metformin in lipopolysaccharideinduced sepsis via suppression of toll-like receptor 4 (TLR4) in heart. Eur J Pharmacol. 2016;772:115-23.

11. Sokos GG, et al. Glucagon-like peptide-1 infusion improves left ventricular ejection fraction and functional status in patients with chronic heart failure. J Card Fail. 2006:12(9):694-9.

12. Marso SP, et al. Liraglutide and cardiovascular outcomes in type 2 diabetes. N Engl J Med. 2016;375(4):311-22.

13. Yabe $D$, Seino $Y$. Incretin actions beyond the pancreas: lessons from knockout mice. Curr Opin Pharmacol. 2013;13(6):946-53.

14. Nystrom $T$, et al. Effects of glucagon-like peptide-1 on endothelial function in type 2 diabetes patients with stable coronary artery disease. Am J Physiol Endocrinol Metab. 2004;287(6):E1209-15.

15. Shiraki A, et al. The glucagon-like peptide 1 analog liraglutide reduces TNFalpha-induced oxidative stress and inflammation in endothelial cells. Atherosclerosis. 2012;221(2):375-82.

16. Liu MM, et al. Protective effect of glucagon-like peptide-1 analogue on cardiomyocytes injury induced by hypoxia/reoxygenation. Zhonghua Nei Ke Za Zhi. 2016;55(4):311-6.

17. Huang $\mathrm{JH}$, et al. Glucagon-like peptide-1 regulates calcium homeostasis and electrophysiological activities of HL-1 cardiomyocytes. Peptides. 2016;78:91-8.

18. Zhang $Y$, et al. Liraglutide protects cardiac microvascular endothelial cells against hypoxia/reoxygenation injury through the suppression of the SR-caXO-ROS axis via activation of the GLP-1R/PI3K/Akt/survivin pathways. Free Radic Biol Med. 2016:95:278-92.

19. Kimura $R$, et al. Glucagon-like peptide-1 (GLP-1) protects against methylglyoxal-induced PC12 cell apoptosis through the PI3K/Akt/mTOR/ GCLC/redox signaling pathway. Neuroscience. 2009;162(4):1212-9.

20. Ladenheim EE. Liraglutide and obesity: a review of the data so far. Drug Des Devel Ther. 2015;9:1867-75

21. Forst T, et al. Addition of liraglutide in patients with type 2 diabetes well controlled on metformin monotherapy improves several markers of vascular function. Diabet Med. 2012;29(9):1115-8.

22. Button $\mathrm{KS}$, et al. Power failure: why small sample size undermines the reliability of neuroscience. Nat Rev Neurosci. 2013;14(5):365-76.

23. Duca FA, et al. Metformin activates a duodenal Ampk-dependent pathway to lower hepatic glucose production in rats. Nat Med. 2015;21(5):506-11.

24. Lin $\mathrm{HZ}$, et al. Metformin reverses fatty liver disease in obese, leptin-deficient mice. Nat Med. 2000;6(9):998-1003.

25. Masoudi FA, et al. Thiazolidinediones, metformin, and outcomes in older patients with diabetes and heart failure: an observational study. Circulation. 2005:111(5):583-90.

26. Knowler WC, et al. Reduction in the incidence of type 2 diabetes with lifestyle intervention or metformin. N Engl J Med. 2002;346(6):393-403.

27. Hivert MF, et al. Lifestyle and Metformin ameliorate insulin sensitivity independently of the genetic burden of established insulin resistance variants in diabetes prevention program participants. Diabetes. 2016;65(2):520-6.

28. Jia J, et al. Neuropharmacological actions of Metformin in stroke. Curr Neuropharmacol. 2015;13(3):389-94.
29. Floyd JS, et al. Case-control study of second-line therapies for type 2 diabetes in combination with metformin and the comparative risks of myocardial infarction and stroke. Diabetes Obes Metab. 2015;17(12):1194-7.

30. $\mathrm{Fu} \mathrm{L}$, et al. Interaction between metformin and leucine in reducing hyperlipidemia and hepatic lipid accumulation in diet-induced obese mice. Metabolism. 2015;64(11):1426-34.

31. Xu T, et al. Effects of metformin on metabolite profiles and LDL cholesterol in patients with type 2 diabetes. Diabetes Care. 2015;38(10):1858-67.

32. Garinis $\mathrm{GA}$, et al. Metformin versus dietary treatment in nonalcoholic hepatic steatosis: a randomized study. Int J Obes. 2010;34(8):1255-64.

33. Loomba R, et al. Clinical trial: pilot study of metformin for the treatment of non-alcoholic steatohepatitis. Aliment Pharmacol Ther. 2009;29(2):172-82.

34. Kashi $Z$, et al. The role of Metformin response in lipid metabolism in patients with recent-onset type 2 diabetes: $\mathrm{HbA1c}$ level as a criterion for designating patients as responders or nonresponders to Metformin. PLoS One. 2016;11(3):e0151543.

35. Bhalla RC, et al. Vascular effects of metformin. Possible mechanisms for its antihypertensive action in the spontaneously hypertensive rat. Am J Hypertens. 1996;9(6):570-6.

36. Isoda $\mathrm{K}$, et al. Metformin inhibits proinflammatory responses and nuclear factor-kappaB in human vascular wall cells. Arterioscler Thromb Vasc Biol. 2006:26(3):611-7.

37. Nauck M, et al. Efficacy and safety comparison of liraglutide, glimepiride, and placebo, all in combination with metformin, in type 2 diabetes: the LEAD (liraglutide effect and action in diabetes)-2 study. Diabetes Care. 2009:32(1):84-90.

38. Croom KF, McCormack PL. Liraglutide: a review of its use in type 2 diabetes mellitus. Drugs. 2009;69(14):1985-2004.

39. Zinman B, et al. Efficacy and safety of the human glucagon-like peptide-1 analog liraglutide in combination with metformin and thiazolidinedione in patients with type 2 diabetes (LEAD-4 met+TZD). Diabetes Care. 2009;32(7): 1224-30.

40. Kalra S, et al. Glucagon-like peptide-1 receptor agonists in the treatment of type 2 diabetes: past, present, and future. Indian J Endocrinol Metab. 2016:20(2):254-67.

41. Nauck MA, Friedrich N. Do GLP-1-based therapies increase cancer risk? Diabetes Care. 2013:36(Suppl 2):S245-52.

\section{Submit your next manuscript to BioMed Central and we will help you at every step:}

- We accept pre-submission inquiries

- Our selector tool helps you to find the most relevant journal

- We provide round the clock customer support

- Convenient online submission

- Thorough peer review

- Inclusion in PubMed and all major indexing services

- Maximum visibility for your research

Submit your manuscript at www.biomedcentral.com/submit
) Biomed Central 